\title{
Vibrio vulnificus: An Environmental and Clinical Burden
}

\author{
Sing-Peng Heng ${ }^{1 \dagger}$, Vengadesh Letchumanan ${ }^{2,3+}$, Chuan-Yan Deng ${ }^{4}$, \\ Nurul-Syakima Ab Mutalib ${ }^{5}$, Tahir M. Khan ${ }^{3,6}$, Lay-Hong Chuah ${ }^{3}$, Kok-Gan Chan ${ }^{2}$, \\ Bey-Hing Goh ${ }^{3,7}$, Priyia Pusparajah ${ }^{1 *}$ and Learn-Han Lee ${ }^{3,7 *}$
}

1 Jeffrey Cheah School of Medicine and Health Sciences, Monash University Malaysia, Bandar Sunway, Malaysia, ${ }^{2}$ Division of Genetics and Molecular Biology, Faculty of Science, Institute of Biological Sciences, University of Malaya, Kuala Lumpur, Malaysia, ${ }^{3}$ Novel Bacteria and Drug Discovery Research Group, School of Pharmacy, Monash University Malaysia, Bandar Sunway, Malaysia, ${ }^{4}$ Zhanjiang Evergreen South Ocean Science and Technology Corporation, Guangdong, China, ${ }^{5}$ UKM Medical Centre, UKM Medical Molecular Biology Institute, Universiti Kebangsaan Malaysia, Kuala Lumpur, Malaysia, ${ }^{6}$ Department of Pharmacy, Absyn University Peshawar, Peshawar, Pakistan, ${ }^{7}$ Center of Health Outcomes Research and Therapeutic Safety (Cohorts), School of Pharmaceutical Sciences, University of Phayao, Phayao, Thailand

\section{OPEN ACCESS}

Edited by:

David Rodriguez-Lazaro, University of Burgos, Spain

Reviewed by: Dapeng Wang,

Shanghai Jiao Tong University, China Dario De Medici,

Istituto Superiore di Sanità, Italy

*Correspondence:

Priyia Pusparajah

priyia.pusparajah@monash.edu Lee Learn-Han

lee.learn.han@monash.edu; leelearnhan@yahoo.com

${ }^{\dagger}$ These authors have contributed equally to this work.

Specialty section

This article was submitted to Food Microbiology a section of the journal Frontiers in Microbiology

Received: 27 March 2017 Accepted: 17 May 2017 Published: 31 May 2017

Citation:

Heng S-P, Letchumanan V, Deng $C-Y$, Ab Mutalib N-S, Khan TM, Chuah L-H,

Chan K-G, Goh B-H, Pusparajah P and Lee L-H (2017) Vibrio vulnificus:

An Environmental and Clinical Burden. Front. Microbiol. 8:997. doi: 10.3389/fmicb.2017.00997
Vibrio vulnificus is a Gram negative, rod shaped bacterium that belongs to the family Vibrionaceae. It is a deadly, opportunistic human pathogen which is responsible for the majority of seafood-associated deaths worldwide. $V$. vulnificus infection can be fatal as it may cause severe wound infections potentially requiring amputation or lead to sepsis in susceptible individuals. Treatment is increasingly challenging as $V$. vulnificus has begun to develop resistance against certain antibiotics due to their indiscriminate use. This article aims to provide insight into the antibiotic resistance of $V$. vulnificus in different parts of the world as well as an overall review of its clinical manifestations, treatment, and prevention. Understanding the organism's antibiotic resistance profile is vital in order to select appropriate treatment and initiate appropriate prevention measures to treat and control V. vulnificus infections, which should eventually help lower the mortality rate associated with this pathogen worldwide.

Keywords: Vibrio vulnificus, prevalence, pathogenesis, treatment, prevention

\section{INTRODUCTION}

The emergence of multidrug resistant strains of bacteria has become an international health crisis as illustrated by statements issued by the World Health Organization (WHO) highlighting antimicrobial resistance as a significant threat to human well-being (WHO, 2014). This crisis is largely attributable to indiscriminate use of antibiotics in clinical medicine as well in the agriculture and aquaculture industries. Antibiotic resistance is not something new, however the number of resistant pathogens, the geographic locations affected, and the extent of resistance in any particular organism are rising. All bacterial infections that were once believed to be treatable with appropriate antibiotics are returning in new leagues resistant to antibiotic therapy (Levy and Marshall, 2004).

There is no doubt that bacterial infection is a significant threat to mankind-human illness as a result of bacterial infection is common. Vibrio species including Vibrio cholerae, Vibrio parahemolyticus, and Vibrio vulnificus are among the common causes of foodborne infections in humans as a result of consumption of contaminated food, particularly seafood. Aside from this, these infections of aquatic livestock by organisms have also been responsible for large-scale losses in the aquaculture industry leading to prophylactic as well as therapeutic use of antimicrobials (Devi et al., 2009; Manjusha and Sarita, 2011; Letchumanan et al., 2014, 2015a). This excessive 
usage of antibiotics has caused the development of multidrug resistance in Vibrio species (Sudha et al., 2014; Letchumanan et al., 2015b).

While the emergence of multidrug resistant strains is already an alarming situation; this scenario is compounded by the dearth of new antibiotics in the pipeline (Rice, 2008; Freire-Moran et al., 2011). This article aims to provide insight into the antibiotic resistance of $V$. vulnificus in different parts of the world as well as an overall review of its clinical manifestations, treatment, and prevention. This information is vital in order to ensure that appropriate treatment is initiated and prevention measures are taken to treat and control V. vulnificus infections, with the aim of eventually lowering the mortality rate associated with this pathogen worldwide.

\section{CHARACTERISTIC OF Vibrio vulnificus}

V. vulnificus belongs to the family Vibrionaceae and is found in warm coastal environments where water temperatures range from $9^{\circ}$ to $31^{\circ} \mathrm{C}$. The preferred habitat of $V$. Vulnificus has been reported to be water temperature in excess of $18^{\circ} \mathrm{C}$ with salinities between 15 and 25 parts per thousand (ppt) (Motes et al., 1998; Jones and Oliver, 2009; Huehn et al., 2014). Therefore, most cases of $V$. vulnificus infection are usually found in tropical or subtropical regions (Strom and Paranjype, 2000). V. vulnificus is classified into three biotypes based on their biochemical characteristics. Biotype 1 strains are predominantly responsible for severe human infection and are found worldwide in salt or brackish water. These biotype strains have been reported to be responsible for the entire disease spectrum mentioned earlier, including primary sepsis associated with the often-quoted fatality rate in excess of 50\% (Horseman and Surani, 2011). Biotype 2 strains are primarily eel pathogens, found in saltwater in Eastern and Western Europe. Biotype 2 strains are capable of causing human infections but cases are rare (Strom and Paranjype, 2000; Oliver, 2005). Comparison of the genomic similarities among the three biotypes revealed biotype 3 to be a hybrid of biotypes 1 and 2. Biotype 3 strains are found in freshwater fish and their geographical range is limited to Israel (Jones and Oliver, 2009). Although biotype 3 is responsible for human infections and may cause serious infections requiring amputation, the reported mortality rate is $<8 \%$ (Zaidenstein et al., 2008).

To cause human infection, V. vulnificus must first survive the inhospitable environment in our bodies and overcome our immune response. It is able to accomplish this due to its innate virulence factors/determinants which enhance its pathogenicity, conferring the ability to survive in the human body (Jones and Oliver, 2009). Severe mechanisms contribute in attachment and invasion of a host, which including pili, $O m p U$, and $I p A$ membrane proteins and flagella (Jung et al., 2005; Goo et al., 2006, 2007; Jones and Oliver, 2009). V. vulnificus are also able to utilize Neu5Ac as a nutrient during infection in humans and survive in highly acidic environments by breaking down amino acids to amines and $\mathrm{CO}_{2}$ (Jeong et al., 2009; Jones and Oliver, 2009). Surface expression of CPS is another virulence factor for $V$. vulnificus that enables it to survive in face of our immune response (Kashimoto et al., 2005). Besides that, RtxA1, Hemolysin (VvhA), and metalloprotease like VvpE and VvpM also contribute in cellular damage and cytotoxicity by causing haemolysis, cell apoptosis, and tissue necrosis, which result in bullous cutaneous lesions characteristics of systemic disease (Miyoshi and Shinoda, 2000; Lee et al., 2011; Lee M. A. et al., 2014).

\section{OCCURRENCE OF Vibrio vulnificus}

$V$. vulnificus infections have been reported in diverse climate zones throughout the world (Table 1) including Denmark, Sweden, Germany, Spain, Turkey, Holland, Belgium, Israel, Italy, Korea, Japan, Taiwan, India, Thailand, Australia, and Brazil (Oliver et al., 1983; Dalsgaard et al., 1996; Bisharat et al., 1999; Torres et al., 2002; Oliver, 2006a,b, 2013; Patridge et al., 2009; Huehn et al., 2014; Karunasagar, 2014). This bacterium is commonly found in seafood samples with studies having reported that $3.5-8 \%$ of seafood samples in Europe, $2.4 \%$ of shrimp from Southeast Asia, 75\% of freshly harvested oysters in India and $100 \%$ of oysters harvested from the Gulf of Mexico during warm months (May to October) contained V. vulnificus (Jones, 2014). Further, analysis of 180 cases in FDA records between 2002 and 2007 have shown that raw oysters is the main source of infection in the US with $92.8 \%$ of infected patients having consumed raw oysters. Studies have shown that there are 95 cases reported with 85 hospitalizations and 35 deaths per year globally (CDC, 2013).

In the United States, $V$. vulnificus is a leading cause of seafood-associated fatality. There are $\sim 50$ cases of $V$. vulnificus infection with 45 hospitalizations and 16 deaths every year (CDC, 2013). V. vulnificus is found to be isolated from Atlantic and Pacific coasts where $74 \%$ of retail oysters in the U.S. contained $V$. vulnificus with the greatest detection frequency from the Gulf of Mexico (Texas, Louisiana, Mississippi, Alabama, and Florida), followed by Mid-Atlantic, North Atlantic, and the Pacific (Oliver, 2006a,b; Jones, 2014). In addition, V. vulnificus can replicate itself in postharvest seafood if it is not cooled immediately, therefore the V. vulnificus level is greater at the time of consumption (retail, market) rather than at harvest (Jones, 2014). V. vulnificus found in the Gulf Coast region with a peak in the onset of both systemic and wound infection between April to September because $V$. vulnificus favors tropical and subtropical region (Strom and Paranjype, 2000). The Florida Department of Health and Rehabilitative Services (HRS) reported 125 confirmed cases of V. vulnificus from 1981 to 1992 (Hlady and Klontz, 1996). As shown in Table 1, there were 422 cases from 23 states reported to the Centers for Disease Control and Prevention (CDC) between 1988 and 1996; out of these, 45\% were wound infections, $43 \%$ were primary septicaemia, and the associated mortality was 38.4\% (Amaro and Biosca, 1996; Hlady and Klontz, 1996). It is likely that the actual incidence of cases of $V$. vulnificus gastroenteritis in the community is higher than documented but that the majority of cases go unreported since the illness is seldom severe enough to require hospitalization (Strom and Paranjype, 2000). Vugia et al. (2013) reported 88 cases of V. vulnificus 


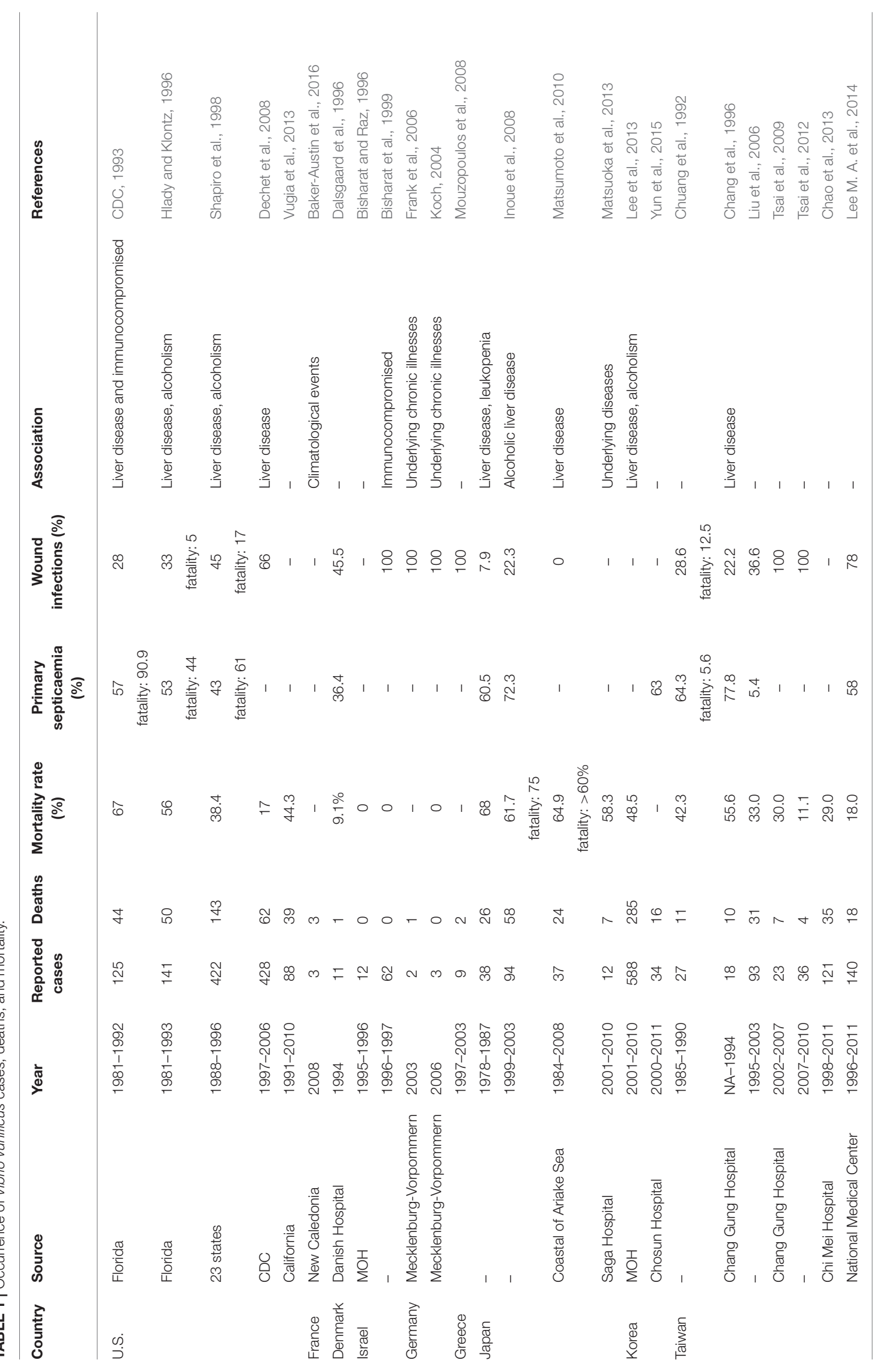


infection in California with a total of 39 deaths from 1991 to 2010.

In New Caledonia, three deaths due to V. vulnificus infection were reported in 2008, all suspected to have been acquired via ingestion of contaminated oysters. All three patients died from primary septicaemia and was significant enough to attract attention as V. vulnificus infections are rare in the South Pacific (CDC, 2011). It was hypothesized that the salinity in Caledonia was significantly reduced due to the heavy precipitation in early 2008, which then indirectly provided a fertile environment for the organisms to proliferate. These examples further suggest that changes in climate may be a contributory factor in increasing risk of V. vulnificus infection (Baker-Austin et al., 2016).

From August 1995 to summer 1996, 25 cases of Vibrio infections were reported to the Epidemiology Department at the Ministry of Health in Israel; out of which 12 cases identified to be $V$. vulnificus (Bisharat and Raz, 1996). There was a subsequent upsurge with 62 cases reported between May 1996 and December 1997. Of these 62 cases, 33 were confirmed cases and 29 were suspected cases without laboratory confirmation; 57 (92\%) developed cellulitis, four with necrotising fasciitis, and one with osteomyelitis, but fortunately, no deaths were reported. Nevertheless, both wound infection and bacteraemia were identified for all 62 cases (Bisharat et al., 1999).

In summer 2003, two cases of $V$. vulnificus infection were reported in Mecklenburg-Vorpommern, Germany. Both patients had open wounds on the legs and one patient died after developing the infection (Frank et al., 2006). In the same region in Germany, three cases of $V$. vulnificus infection were reported in summer 2006, all involving patients with wound infections who were treated with antibiotics (Koch, 2004). A retrospective study looking at the time period between June 1997 and July 2003, identified nine patients with lower extremity $V$. vulnificus infection, all of whom had associated foot injuries. Postoperative complications led to two fatalities while others were all treated with antibiotics or amputation (Mouzopoulos et al., 2008).

Unsurprisingly, there is geographical variation in the primary source of infection based on dietary differences. For example, a mud shrimp, Upogebia major rather than raw oysters represent the primary source of $V$. vulnificus infection in Japan (Karunasagar, 2014). It is possible that other kinds of seafood may also cause infection as demonstrated by a study conducted in a Chinese local seafood market which found that $100 \%$ of razor clams, $100 \%$ of tiger prawns, and $56 \%$ of shrimp, were contaminated with $V$. vulnificus with bacterial levels up to $\sim 70,000$ per gram (Jones, 2014). In Japan, a questionnairebased retrospective study was conducted in 1,693 hospitals, which showed a total of 93 reported cases of $V$. vulnificus infection in Japan between 1999 and 2003. Out of this total, 68 cases $(72.3 \%)$ presented with septicaemia and the mortality rate was $75 \%$. The prognosis of primary septicaemia was found to be worse than that of wound infection $(P<0.001$; Inoue et al., 2008). Recently, Matsuoka et al. (2013) investigated and reported 12 patients with $V$. vulnificus-induced necrotic fasciitis-7 out of 12 died, giving a mortality rate of $58.3 \%$ and without exception, all patients involved had underlying diseases (Matsuoka et al., 2013).
In neighboring Korea, the National Notifiable Diseases Surveillance System reported 588 confirmed V. vulnificus infection cases from 2001 to 2010. Out of all cases reported, 285 were fatal, giving a mortality rate of $48.5 \%$ (Lee et al., 2013). In a separate report, 34 cases were reported in Chosun University Hospital from January 2000 to December 2011, with 16 fatalities (Yun et al., 2015). In Chang gung Memorial Hospital, Taiwan, 18 patients were identified with $V$. vulnificus infection over an unspecified period of time. Of all cases, 14 patients manifested with primary septicaemia and four patients with wound infection with an overall mortality of $55.6 \%$ in this study (Chang et al., 1996). As seen in Table 1, from January 2007 to June 2010, among 143 patients with necrotizing fasciitis, 36 patients were identified to have $V$. vulnificus infections. Of all the patients with $V$. vulnificus infections, there were four fatalities yielding a mortality rate of 11.1\% (Tsai et al., 2012). In Chi Mei Medical Center, 121 patients who were confirmed with $V$. vulnificus between July 1998 and June 2011 were recruited into a study. Of all patients with infections, 35 patients died yielding a mortality rate of 29\% (Chao et al., 2013).

\section{HEALTHCARE BURDEN}

Bacterial infections are a constant strain/burden on the healthcare sector. In the U.S., the annual health costs of seafood-related diseases were calculated to be US\$ 350 million with direct exposure to V. vulnificus, Vibrio parahaemolyticus, Vibrio alginolyticus, and aerosolized Karenia brevis accounting for over US\$30 million. Studies have shown that premature deaths (i.e., death before the age of 75 years) accounted for a large proportion of the total cost of seafood-related illness treatment costs (US\$306 million), followed by medical care (US\$25 million), hospitalization (US\$6 million), and loss of productivity (US\$15 million), and these inevitably become a great healthcare burden to the U.S. (Ralston et al., 2011).

On further breakdown, V. vulnificus had the dubious honor of being the costliest marine-borne pathogen in the study with an annual cost of illness 10 times higher than any other pathogen, accounting for $66 \%$ of seafood-related illness health costs and $26 \%$ of the total health costs. Even more worryingly, V. vulnificus accounts for $1 / 3$ of the total seafood-related illness and more than $85 \%$ of the costs of direct exposure to Vibrio pathogen. These were due primarily to a high rate of premature death with a mortality rate of $31 \%$ for seafood-related infection and $18 \%$ for infections from direct exposure. This should garner the significant attention as premature death costs US\$ 238 million, which accounts for $99 \%$ of the total $V$. vulnificus health costs and $75 \%$ of the total cost of premature death (Ralston et al., 2011).

$V$. vulnificus are usually susceptible to most antibiotics of veterinary and human significance (Oliver, 2006a). However, the extensive use of antibiotics in health care, agriculture, and aquaculture systems has led to the increase in antibiotic resistance in many bacterial genera including Vibrio species over the past few decades (Cabello, 2006; Letchumanan et al., 
2015a,b,c). V. vulnificus in seafood and aquatic environments are exhibiting resistance to multiple antibiotics due to the misuse of antibiotics (Elmahdi et al., 2016). As multiple-antibiotic resistant bacteria pose a threat in both to fish and shellfish farming and human health, appropriate actions need to be taken as it raises serious public health and economic concerns (WHO, 2014). $V$. vulnificus resistance toward common antibiotics has reached alarming levels in many countries (Table 2) which has serious implications on the treatment methods for bacterial infections (WHO, 2014).

In the U.S., V. vulnificus is a leading cause of seafoodassociated fatalities; there are $\sim 50$ cases of $V$. vulnificus infection with 45 hospitalizations and 16 deaths every year (CDC, 2013). Primary septicaemia, which is the main characteristic of $V$. vulnificus infection in humans is associated with a high mortality rate (Feldhusen, 2000). A study in South Carolina and Georgia involving clinical and environmental V. vulnificus isolates showed that $45 \%$ of the environmental isolates were resistant to three or more classes of antibiotics while $17.3 \%$ were resistant to 8 or more antibiotic agents. This includes the drugs that are usually prescribed for $V$. vulnificus infections, including doxycycline, tetracycline, aminoglycosides, and cephalosporin (Baker-Austin et al., 2009).

In Germany, Vibrio infections occur sporadically but incidence peaks after extreme heatwaves (Huehn et al., 2014). Bier et al. (2015) studied the antibiotic resistance profile of $V$. vulnificus and $V$. cholerae that were recovered along the Baltic Sea and North Sea coastline as well as the estuaries of the rivers Ems and Weser. Results showed that $V$. vulnificus isolates were susceptible to all the antimicrobial agents tested including quinolones, tetracycline, folate pathway inhibitors, carbapenems, cephalosporins, and aminopenicillins with or without B-lactamase inhibitors, while only $2 \%$ of the isolates showed resistance toward streptomycin (Bier et al., 2015). This results showed a variation in the antibiotic resistance pattern when compared with the findings from Baker-Austin et al. (2009). This suggest that the usage of antibiotics in different aquaculture and clinical settings influence the resistance pattern among the Vibrio species.

The antibiotic resistance profile of $V$. vulnificus has also been studied in Asian countries. In China, the antibiotic resistance profile was studied in $33 \mathrm{~V}$. vulnificus isolates from retail shrimps in Hangzhou which were tested against 21 antibiotics. The findings showed that they were resistant or intermediately resistant to cefepime $(3.03 \%)$, tetracycline (6.06\%), aztreonam (24.24\%), streptomycin (45.45\%), gentamycin (93.94\%), tobramycin (100\%), and cefazolin (100\%). Fortunately, all the isolates obtained were sensitive to ampicillin, ampicillin-sulbactam, piperacillin-tazobactam, cephalothin, ceftriaxone, cefetaxime, ceftazidime, imipenem, ciprofloxacin, levofloxacin, nalidixic acid, trimethoprim-sulfamethoxazole, chloramphenicol, and nitrofurantoin (Pan et al., 2013).

Li et al. (1999) reported the antibiotic susceptibility of 51 Vibrio strains collected from Sparus sarba from May 1995 to February 1997 in Hong Kong. The study found that all strains were sensitive to ceftriaxone, streptomycin, nalidixic acid, and rifampicin. However, there four strains that were resistant to ampicillin, cefuroxime, tetracycline, trimethoprim, and aminoglycosides including gentamicin, amikacin, kanamycin, netilimicin (Li et al., 1999).

In India, between September 2010 and March 2011, a study of pathogenic Vibrio strains which made up $2 \%$ of $V$. vulnificus isolates from four retail markets in Cochin, India were tested for their susceptibility to various classes of antibiotics. This study showed that all $V$. vulnificus isolates were susceptible to chloramphenicol, tetracycline, and nalidixic acid, and were all resistant to ampicillin, amoxicillin, carbenicillin, colistin, ceftazidin, cephalothin, and streptomycin (Sudha et al., 2014).

\section{CLINICAL MANIFESTATION}

$V$. vulnificus can cause severe, potentially life-threatening infection in susceptible patients. This bacterium is transmitted via seafood handling or consumption of contaminated seafood, especially raw or undercooked oysters or through direct inoculation into open wounds (Gulig et al., 2005; Dechet et al., 2008; Jones and Oliver, 2009; Daniel, 2011). Gastroenteritis usually results from the consumption of contaminated seafood (raw oysters) and the patient may present with nausea, vomiting, and abdominal pain which often progresses to fever, chills, and cutaneous manifestations (Haq and Dayal, 2005). Since these cases generally do not result in systemic shock or localized cellulitis, the vast majority of these cases are unreported.

In certain cases, $V$. vulnificus infection can be fatal particularly when it results in primary septicaemia and necrotizing fasciitis (Strom and Paranjype, 2000). Septicaemia appears to be the most common or in some data a close second presentation of infection, and has the worst outcome with mortality rate of more than 50\% (Hlady and Klontz, 1996; Feldhusen, 2000). The portal of entry is believed to be the small intestine or cecum, but the ileum is considered the most likely site (Chen et al., 2002). Primary septicaemia is characterized by bacteremia without any obvious focus of infection and usually presents with sudden onset of fever and chills, often accompanied by vomiting, diarrhea, abdominal pain, and pain in the extremities within 7 days after ingestion of contaminated seafood; though symptom onset might be delayed for up to 14 days (Chen et al., 2002; Haq and Dayal, 2005). Within the first $24 \mathrm{~h}$ after the onset of illness, secondary cutaneous lesions such as cellulitis, bullae, and ecchymoses begin to appear on patient's extremities (Haq and Dayal, 2005). Besides that, septic shock (systolic blood pressure $<90 \mathrm{mmHg}$ ), mental status changes (obtundation, lethargy, or disorientation), and thrombocytopenia were also reported in patients with primary septicaemia (Blake et al., 1979; Klontz et al., 1988; Shapiro et al., 1998). Primary septicaemia is fatal in 60$75 \%$ of cases with development of hypotension within $12 \mathrm{~h}$ of admission representing a particularly poor prognostic factor, as these cases are twice more likely to die compared to infected patients with normal blood pressure (Klontz et al., 1988).

Necrotizing fasciitis usually results from handling contaminated seafood or exposure of open wounds to contaminated water (Klontz et al., 1988; Dechet et al., 2008; Jones and Oliver, 2009). Severity of the infection may vary from 


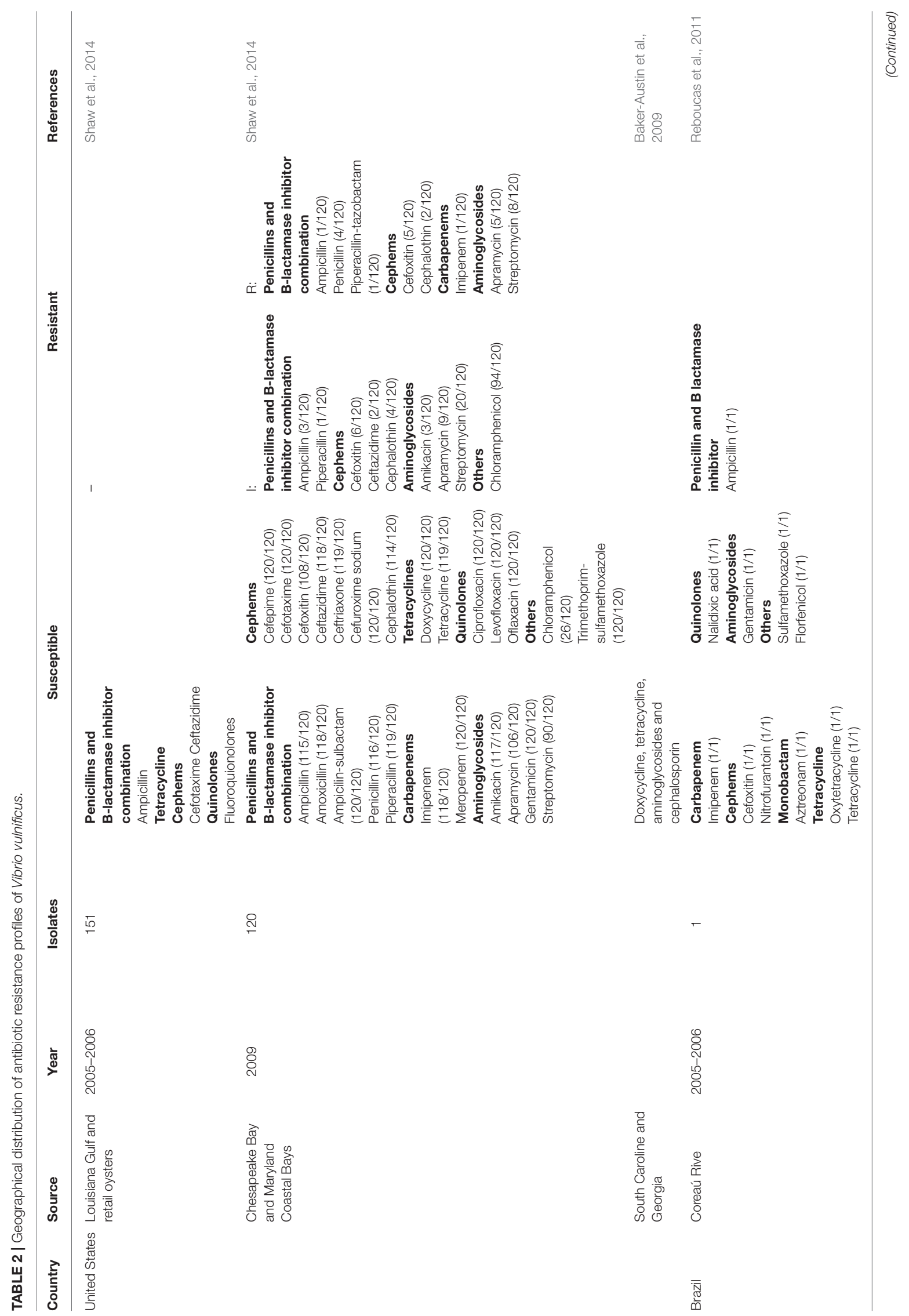




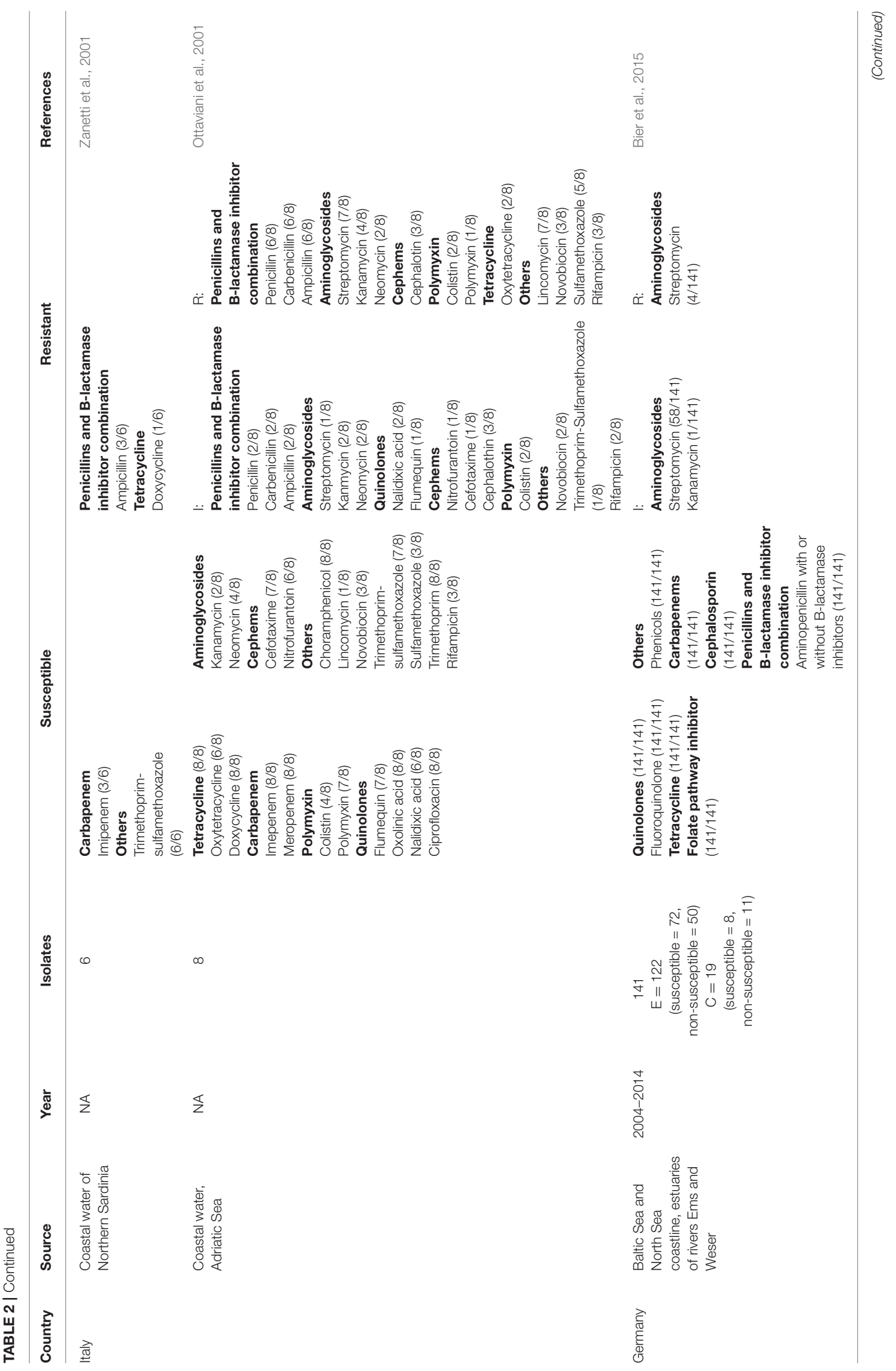




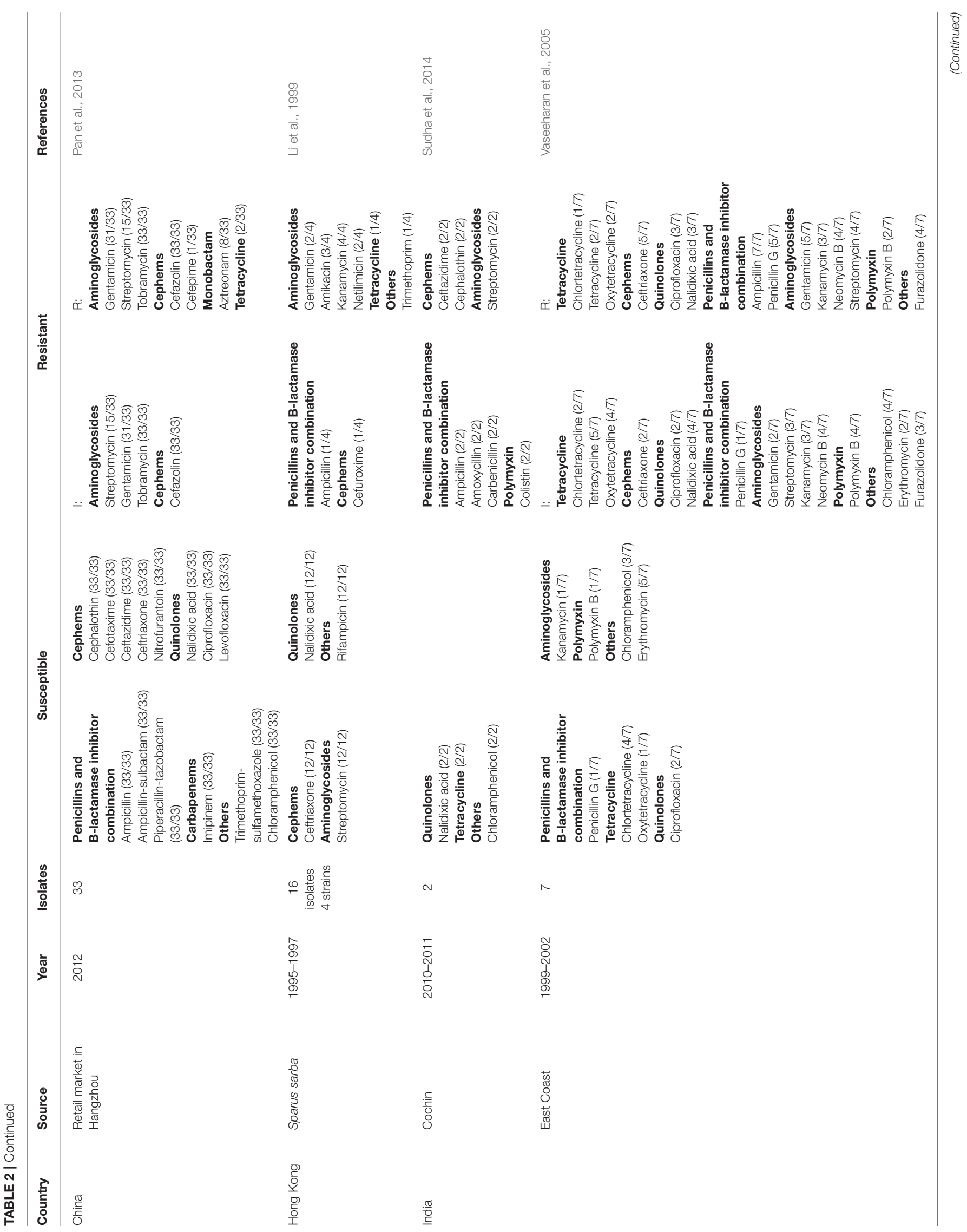




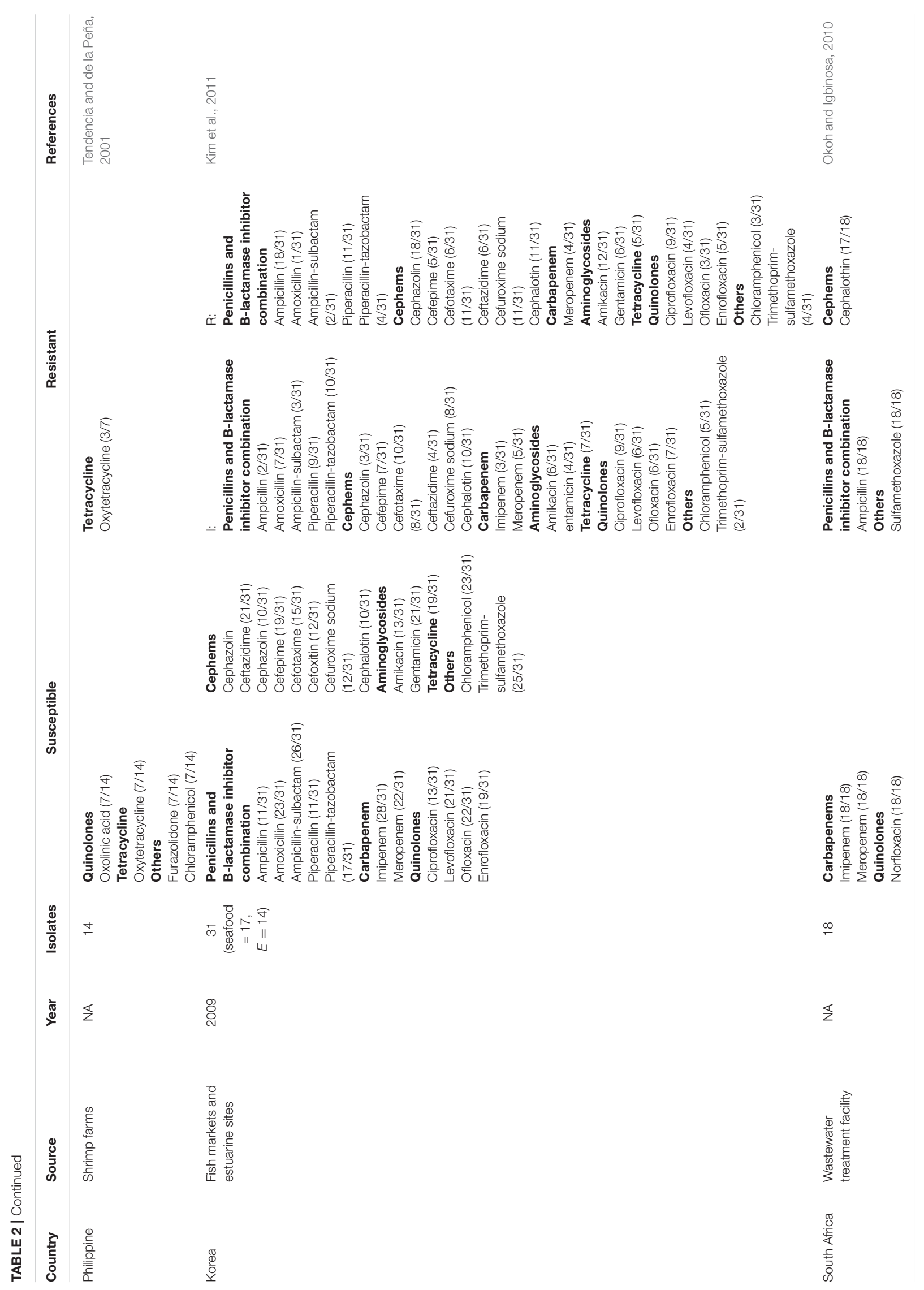


mild to severe with symptoms occurring within 7 days, but could also be delayed as long as 12 days from exposure (Horseman and Surani, 2011). Wound infection can advance to cellulitis and become necrotic but fortunately its fatality rate is lower than primary septicaemia, ranging from 20 to $30 \%$ (Strom and Paranjype, 2000; Karunasagar, 2014). In contrast to primary septicaemia, necrotizing fasciitis is limited to the affected area and metastatic infection is not observed (Horseman and Surani, 2011).

Besides the above-mentioned presentations, it should be noted that patients may also have atypical presentations including spontaneous bacterial peritonitis, pneumonia, endometritis, meningitis, septic arthritis, osteomyelitis, endophthalmitis, and keratitis, all of which have been reported in recent years (Penland et al., 2000; Johnson and Arnett, 2001; Jung et al., 2005).

\section{TREATMENT AND PREVENTION}

Prompt treatment with appropriate antibiotics is essential for optimal patient outcomes, particularly in more severe manifestations such as systemic septicaemia and wound infections (Krovacek et al., 1994; Moreno and Landgraf, 1998). Regardless of the route of infection, V. vulnificus infection responds positively to antibiotics and it has been clearly demonstrated that the greater the delay in the initiation of treatment, the higher the fatality rate (Rodrigues et al., 1992; Amaro et al., 1994; Krovacek et al., 1994; Moreno and Landgraf, 1998). Several classes of antimicrobials are suitable for treatment of V. vulnificus infection. According to the CDC, doxycycline, and ceftazidime are the antibiotics of choice for $V$. vulnificus infections in adults, while in children with $V$. vulnificus wound infection, the recommended treatment is trimethoprimsulfamethoxazole (co-trimoxazole) and an aminoglycoside while doxycycline and fluoroquinolones are contraindicated (CDC, 2013). Infectious Diseases Society of America (IDSA) suggests doxycycline with ceftriaxone or cefotaxime as the first-line antimicrobial agent in adults with $V$. vulnificus infections (Stevens et al., 2014).

However, the first-line antimicrobial agents suggested above may no longer be applicable to all countries with $V$. vulnificus infection. By correlating both the reported resistance profile mentioned in Table 2 and the recommended treatment by IDSA and $\mathrm{CDC}$, antibiotics should be tailored in different countries as the first-line antimicrobial agent might no longer be applicable to patients with V. Vulnificus infection. For example, doxycycline, the antibiotic that is been suggested as first-line treatment by both the CDC and IDSA has shown intermediate resistant profile (1/6) in Italy (Zanetti et al., 2001). Where else, ceftazidime, one of the first-line treatment measures suggested by the IDSA has been reported to have an intermediate resistant profile (2/120) in the U.S. (Shaw et al., 2014) and resistant (2/2) in India (Sudha et al., 2014). Therefore, based on the current evidence, a more appropriate choice would be cefotaxime and ceftriaxone. However, even here there are challenges as ceftriaxone, one of the drugs of choice from the group cephem that has been chosen as one of the first-line drug, also shows an intermediate resistant
(2/7) to a resistant profile (5/7) in India (Vaseeharan et al., 2005). As for children with $V$. vulnificus infection, co-trimoxazole has an intermediate resistant profile (1/8) in Italy and resistant profile $(8 / 8)$ in South Africa. While aminoglycosides are also safe to use in children with $V$. vulnificus infection, it has an intermediate resistant and resistant profile in Italy, Germany, and China; and resistant profile alone in Hong Kong and India. With all the evidence, it is clearly vital for clinicians and microbiologists to work with policy makers to review updated resistance profile in that particular country in order to facilitate usage of the most appropriate antibiotics to maximize the treatment efficacy.

Other than conventional medication mentioned above, it is essential for patients with severe soft tissue infection to undergo surgery (Hsueh et al., 2004; Park et al., 2009) as antimicrobial therapy is usually ineffective due to the thrombosis of the blood vessels supplying the infected area (Horseman and Surani, 2011). Aggressive surgical debridement or amputation is necessary to remove necrotic tissues and the prognosis is good when early debridement and fasciotomy are performed (Kuo et al., 2007).

CDC has published recommendations to prevent $V$. vulnificus infections. Among the preventive measures to be taken are to avoid eating raw oysters or shellfish especially those harvested from warm salt and brackish water, avoid exposure of open wounds to warm salt and brackish water, wear protective clothing (gloves) when handling raw shellfish, and wear protective footwear (wading shoes) when wading in warm salt or brackish water (French et al., 1989).

V. vulnificus can rapidly multiply in harvested seafood if it is not cooled immediately. Without proper storage, $V$. vulnificus levels may be significantly increased when the seafood reaches point of sale and eventual consumption (retail, market) compared to at harvest (Jones, 2014). According to U.S. regulations, commercial shellfish should be refrigerated within $10 \mathrm{~h}$ of harvest when the water temperature exceeds $27^{\circ} \mathrm{C}$ because temperature seems to have a role in influencing bacterial concentration (Ghazaleh et al., 2014; Karunasagar, 2014). Freezing combined with frozen storage and high hydrostatic pressure are the recommended postharvest treatment for oysters in the U.S. (Karunasagar, 2014). Based on FAO/WHO risk assessment, the Codex Committee on Food Hygiene has also developed a Code of Hygienic Practice for control of Vibrio spp. in seafood with an annex on control measures for $V$. vulnificus in bivalve molluscs (Karunasagar, 2014). U.S. FDA and the Interstate Shellfish Sanitation Conference regulate the hazard analysis critical control points (HACCP) for time or temperature controls in order to minimize the exposure of shellfish to elevated temperatures and include defined minimum time from harvest to refrigeration, rate of refrigeration, and allowed time for refrigerated storage (NSSP, 2005).

In terms of prevention, effective vaccines would help in reducing the impact of $V$. vulnificus infection while certain antibiotics are important for protective immunity (LaFrentz and Shoemaker, 2015). In a recent study, American eels (Anguilla rostrata) were immunized with a recombinant bivalent expressed outer membrane protein (OMP) of $V$. vulnificus and Aeromonas hydrophila and the immunogenicity of this novel vaccine antigen was evaluated (Guo et al., 2015). Results showed that the 
expressed bivalent protein of OmpU of V. vulnificus and Omp porin II of A. hydrophila gave a good protective response against the two mentioned pathogens in the American eel under laboratory conditions (Guo et al., 2015). It is said that in order to develop an effective vaccine, priority should be given to immunogenic OMPs (Guo et al., 2015).

A passive immunization experiment was carried out recently to identify the role of antibodies against $V$. vulnificus infection (LaFrentz and Shoemaker, 2015). Results showed that specific antibodies have a role in protection of tilapia against infection and suggested that shared immunogenic antigens also play a role in protection against heterologous isolates (LaFrentz and Shoemaker, 2015). Another study targeted the C-terminal region (amino acid 3491-4701) of the pathogenic RTX (MARTX $\mathrm{Vv}_{\mathrm{v}}$ or RtxA1) protein and found that it successfully induced a protective immune response against $V$. vulnificus (Lee T. H. et al., 2014). Further, experiments with laboratory rodents injected with recombinant RtxA1-C protein with adjuvant also showed a longlasting antibody response and significantly reduced bacterial load in the blood (Lee T. H. et al., 2014). Therefore, this study suggested that immunization against $\mathrm{C}$-terminal region of RtxA1 may be an effective approach in the both prevention and therapy of $V$. vulnificus (Lee T. H. et al., 2014).

Given that the increased use of antibiotics in aquaculture resulted in the emergence of antibiotic resistance, considerable effort has been made in seeking alternative ways to control infections. Quorum sensing (QS) has been proposed to be one of the effective ways to attenuate virulence of organisms (Defoirdt et al., 2004). Quorum sensing is a process of bacterial cell-to-cell communication involving production, release, and detection of small signal molecules, which are also known as auto-inducers (Nealson et al., 1970; Ng and Bassler, 2009). These signal molecules are constantly produced and accumulated as the cells grow (Henke and Bassler, 2004; Antunes et al., 2011). Quorum sensing is also useful in monitoring bacterial cell densities and alter bacterial gene expression in a cell density-dependent manner (Ng and Bassler, 2009). Several techniques have been proposed in aiming to not only inactivating the signal molecule, but also to disrupt the signal detection in Vibrios. Defoirdt and colleagues has proposed a potential solution by distruption of QS in order to control the widespread antimicrobial resistance phenomenon (Defoirdt et al., 2004, 2011). The methods include (1) Inhibiting signal molecule biosynthesis, (2) Quorum sensing antagonist using both natural and synthetic halogenated furanones, antagonistic quorum sensing molecules, and nonspecific exudates of higher plants and algae, (3) Chemical inhibition by oxidized halogen antimicrobials, (4) Disruption of signal molecule by bacterial lactonases and acylases, and

\section{REFERENCES}

Amaro, C., and Biosca, E. G. (1996). Vibrio vulnificus biotype 2, pathogeneic for eels, is also an opportunistic pathogen for humans. Appl. Environ. Microbiol. $62,1454$.

Amaro, C., Biosca, E. G., Fouz, R., Toranzo, A. E., and Garay, E. (1994). Role of iron, capsule, and toxins in the pathogenicity of Vibrio vulnificus biotype 2 for mice. Infect. Immun. 62, 759.
(5) By applying quorum sensing agonists (Defoirdt et al., 2004).

QS disrupting compounds is also known as antipathogenic compounds because of its characteristics in attenuating virulence without affecting the growth of the bacteria. The QS disrupting compounds mentioned above were shown to have no effect toward the growth of the Vibrios and thus do not pose any selective pressure for the development of resistance. The fact that the probability of resistance development is smaller compare to the usage of antibiotics makes QS an attractive biocontrol strategy (Defoirdt et al., 2007).

\section{CONCLUSION}

V. vulnificus is a potentially fatal infection that represents a great health care burden in certain countries. The emergence of multidrug resistant $V$. vulnificus with highly variable regional resistance profiles is a significant healthcare concern. It is essential to gain a more thorough understanding of the antibiotic resistance profile in different countries which is key to drawing up appropriate clinical practice guidelines for treatment and prevention of this potentially lethal pathogen. Efforts to create an effective vaccine are currently underway but are still in early stages, and identifying effective medical therapy seems to be the more immediate goal. Besides the effort of the researchers, both patients and clinicians also have to be educated in terms of effective prevention measures and antimicrobial resistance profile for an effective therapy in order to lower the fatality rate more convincingly. Ultimately, it is also key to find ways to limit antibiotic use in order to prevent increasing emergence of drug resistant microorganisms.

\section{AUTHOR CONTRIBUTIONS}

SPH and VL performed the literature search and writing of the manuscript. CYD, NSAM, TMK, LHC, KGC, BHG, PP, and LHL provided critical review and insight to improve the writing. The research project was conceptualize by LHL.

\section{ACKNOWLEDGMENTS}

This work was supported by PVC Award Grant (Project No. PVC-ECR-2016), MOSTI ScienceFund Grant (Project No. 0602-10-SF0300) and External Industry Grants (Biotek Abadi Vote no. GBA-808138 and GBA-808813) awarded to LHL, University of Malaya for High Impact Research Grant (UMMOHE HIR Nature Microbiome Grant No. H-50001-A000027 and No. A000001-50001) awarded to KGC.

Antunes, L. C., Ferreira, R. B., Buckner, M. M., and Finlay, B. B. (2011). Quorum sensing in bacterial virulence. Microbiology 156, 2271-2282. doi: 10.1099/mic.0.038794-0

Baker-Austin, C., McArthur, J. V., Lindell, A. H., Wright, M. S., Tuckfield, R. C., Gooch, J., et al. (2009). Multi-site analysis reveals wide-spread antibiotic resistance in the marine pathogen Vibrio vulnificus. Microb. Ecol. 57, 151-159. doi: 10.1007/s00248-008-9 413-8 
Baker-Austin, C., Trianes, J., Gonzalez-Escalona, N., and Martinez-Urtaza, J. (2016). Non-cholera vibrios: the microbial barometer of climate change. Trends Microbiol. 25, 1-9. doi: 10.1016/j.tim.2016.09.008

Bier, N., Schwarts, K., Guerra, B., and Strauch, E. (2015). Survey on antimicrobial resistance patterns in Vibrio vulnificus and Vibrio cholera non-O1/non-O139 in Germany reveals carbapenemase-producing Vibrio cholera in coastal waters. Front. Microbiol. 6:1179. doi: 10.3389/fmicb.2015.01179

Bisharat, N., Agmon, V., Finkelstein, R., Raz, R., Ben-Dror, G., Lerner, L., et al. (1999). Clinical, epidemiological, and microbiological features of Vibrio vulnificus biogroup 3 causing outbreaks of wound infection and bacteraemia in Israel. Lancet 354, 1421-1424. doi: 10.1016/S0140-6736(99)02471-X

Bisharat, N., and Raz, R. (1996). Vibrio infection in Israel due to changes in fish marketing. Lancet 348, 1585-1586. doi: 10.1016/S0140-6736(05)6 6199-5

Blake, P. A., Merson, M. H., Weaver, R. E., Hollis, D. G., and Heublein, P. C. (1979). Disease caused by a marine Vibrio. Clinical characteristics and epidemiology. N.Engl. J. Med. 300, 1-5. doi: 10.1056/NEJM197901043000101

Cabello, F. C. (2006). Heavy use of prophylactic antibiotics in aquaculture: a growing problem for human and animal health and for the environment. Environ. Microbiol. 8, 1137-1144. doi: 10.1111/j.1462-2920.2006. 01054.x

Centers for Disease Control and Prevention (CDC) (1993). Vibrio vulnificus Infections Associated with Raw Oyster Consumption: Florida, 1981-1992. MMWR, Vol. 42, 405-405.

Centers for Disease Control and Prevention (CDC) (2011). Fatal Vibrio vulnificus Infection Associated with Easting Raw Oysters. New Caledonia. Available online at: www. cdc.gov/eid

Centers for Disease Control and Prevention (CDC) (2013). Vibrio vulnificus. Centers for Disease Control and Prevention. Atlanta. Available online at: http://www.cdc.gov/vibrio/vibriov.html

Chang, J. J., Sheen, I. S., Peng, S. M., Chen, P. C., Wu, C. S., and Leu, H. S. (1996). Vibrio vulnificus infection: report of 8 cases and review of cases in Taiwan. Changgeng Yi Xue Za Zhi. 17, 339-346.

Chao, W. N., Tsai, C. F., Chang, H. R., Chna, K. S., Su, C. H., Lee, Y. T., et al. (2013). Impact of timing of surgery on outcome of Vibrio vulnificus-related necrotizing fasciitis. Am. J. Surg. 206, 32-39. doi: 10.1016/j.amjsurg.2012.08.008

Chen, Y., Satoh, T., and Tokunaga, O. (2002). Vibrio vulnificus infection in patients with liver disease: report of five autopsy cases. Virchows Arch. 441, 88-92. doi: 10.1007/s00428-002-0613-1

Chuang, Y. C., Yuan, C. Y., Liu, C. Y., Lan, C. K., and Huang, A. H. (1992). Vibrio vulnificus infection in Taiwan: report of 28 cases and review of clinical manifestations and treatment. Clin. Infect. Dis. 15, 271-276. doi: $10.1093 /$ clinids/15.2.271

Dalsgaard, A., Frimodt-Moller, N., Bruun, B., Hoi, L., and Larsen, J. L. (1996). Clinical manifestation and molecular epidemiology of Vibrio vulnificus infections in Denmark. Eur. J. Clin. Micriobiol. Infect. Dis. 15, 227-232. doi: 10.1007/BF01591359

Daniel, N. A. (2011). Vibrio vulnificus oysters: pearls and perils. Clin. Infect. Dis. 52, 788-792. doi: $10.1093 / \mathrm{cid} / \mathrm{ciq} 251$

Dechet, A. M., Yu, P. A., Koram, N., and Painter, J. (2008). Non-foodborne Vibrio infection: an important cause of morbidity and mortality in the United States, 1997-2006. Clin. Infect. Dis. 77, 970-976. doi: 10.1086/529148

Defoirdt, T., Boon, N., Bossier, P., and Verstraete, W. (2004). Disruption of bacterial quorum sensing: an unexplored strategy to fight infections in aquaculture. Aquaculture 240, 69-88. doi: 10.1016/j.aquaculture.2004.06.031

Defoirdt, T., Boon, N., Sorgeloos, P., Verstraete, W., and Bossier, P. (2007). Alternatives to antibiotics to control bacterial infections: luminescent vibriosis in aquaculture as an example. Trends Biotechnol. 25:10. doi: 10.1016/j.tibtech.2007.08.001

Defoirdt, T., Sorgeloos, P., and Bossier, P. (2011). Alternatives to antibiotics for the control of bacterial disease in aquaculture. Microbiology 14, 251-258. doi: 10.1016/j.mib.2011.03.004

Devi, R., Surendran, P. K., and Chakraborty, K. (2009). Antibiotic resistance and plasmid profiling of Vibrio parahaemolyticus isolated from shrimp farms along the coast of India. World J. Microbiol. Biotech. 25, 2005-2012. doi: 10.1007/ s11274-009-0101-8
Elmahdi, S., DaSilva, L. V., and Parveen, S. (2016). Antibiotic resistance of Vibrio parahaemolyticus and Vibrio vulnificus in various countries: a review. Food Microbiol. 57. 128-134. doi: 10.1016/j.fm.2016.02.008

Feldhusen, F. (2000). The role of seafood in bacterial foodborne diseases. Microbes Infect. 2, 1651-1660. doi: 10.1016/S1286-4579(00)01321-6

Frank, C., Littmann, M., Alpers, K., and Hallauer, J. (2006). Vibrio vulnificus wound infections after contact with the Baltic Sea, Germany. Euro. Surveill. 11, 3024

Freire-Moran, L., Aronsson, B., Manz, C., Gyssens, I. C., So, A. D., Monnet, D. L., et al. (2011). Critical shortage of new antibiotics in development against multidrug-resistant bacteria time to react is now. Drug Resist. Update. 14, 118-124. doi: 10.1016/j.drup.2011.02.003

French, G. L., Woo, M. L., Hui, Y. W., and Chan, K. Y. (1989). Antimicrobial susceptibilities of halophilic vibrios. J. Antimicrob. Chemother. 24, 183-194. doi: $10.1093 / \mathrm{jac} / 24.2 .183$

Ghazaleh, M. N., Froelich, B. A., and Noble, R. T. (2014). The effect of storage time on Vibrio spp. and fecal indicator bacteria in an Isco auto-sampler. J. Microbiol. Meth. 104, 109-116. doi: 10.1016/j.mimet.2014.06.021

Goo, S. Y., Ham, Y. S., Kim, W. H., Lee, K. H., and Park, S. J. (2007) Vibrio vulnificus IlpA-induced cytokine production is mediated by Tolllike receptor 2. J. Biol. Chem. 282, 27647-27658. doi: 10.1074/jbc.M7018 76200

Goo, S. Y., Lee, H. J., Kim, W. H., Han, K. L., Park, D. K., Lee, H. J., et al. (2006). Identification of OmpU of Vibrio vulnificus as a fibronectin-binding protein and its role in bacterial pathogenesis. Infect. Immun. 74, 5586-5594. doi: 10.1128/IAI.00171-06

Gulig, P. A., Bourdage, K. L., and Starks, A. M. (2005). Molecular pathogenesis of Vibrio vulnificus. J. Microbiol. 43, 118-131.

Guo, S. L., Lu, P. P., Feng, J. J., Zhao, J. P., Lin, P., and Duan, L. H. (2015). A novel recombinant bivalent outer membrane protein of Vibrio vulnificus and Aeromonas hydrophila as a vaccine antigen of American eel (Anguilla rostrata). Fish Shellfish Immunol. 43, 477-484. doi: 10.1016/j.fsi.2015. 01.017

Haq, S. M., and Dayal, H. H. (2005). Chronic liver disease and consumption of raw oysters: a potentially lethal combination- a review of Vibrio vulnificus septicemia. Am. J. Gastroenterol. 100, 1195-1199. doi: $10.1111 / j .1572-0241.2005 .40814 . x$

Henke, J. M., and Bassler, B. L. (2004). Bacterial social engagements. Trends Cell Biol. 14, 648-656. doi: 10.1016/j.tcb.2004.09.012

Hlady, W. G., and Klontz, K. C. (1996). The epidemiology of Vibrio infections in Florida, 1981-1993. J. Infect. Dis. 173, 1176-1183. doi: $10.1093 /$ infdis/173.5.1176

Horseman, M. A., and Surani, S. (2011). A comprehensive review of Vibrio Vulnificus: an important cause of severe sepsis and skin and soft-tissue infection. Int. J. Infect. Dis. 15, 157-166. doi: 10.1016/j.ijid.2010.11.003

Hsueh, P. R., Lin, C. Y., Tang, H. J., Lee, H. C., Liu, J. W., Liu, Y. C., et al. (2004). Vibrio vulnificus in Taiwan. Emer. Infect. Dis. 10, 1363-1368. doi: 10.3201/eid1008.040047

Huehn, S., Eichhorn, C., Urmersbach, S., Bredidenbach, J., Bachlars, S., Bier, N., et al. (2014). Pathogen vibrios in environmental, seafood and clinical sources in Germany. Int. J. Med. Microbiol. 304, 843-850. doi: 10.1016/j.ijmm.2014. 07.010

Inoue, Y., Ono, T., Matsui, T., Miyasaka, J., Kinoshita, Y., and Ihn, H. (2008). Epidemiological survey of Vibrio vulnificus infection in Japan between 1999 and 2003. J. Dermatol. 35, 129-139. doi: 10.1111/j.1346-8138.2008.00432.x

Jeong, H. G., Oh, M. H., Kim, B. S., Lee, M. Y., Han, H. J., and Choi, S. H. (2009). The capability of catabolic utilization of N-Acetylneuraminic acid, a sialic acid, is essential for Vibrio vulnificus pathogenesis. Infect. Immun. 77, 3209-3217. doi: 10.1128/IAI.00109-09

Johnson, R. W., and Arnett, F. C. (2001). A fatal case of Vibrio vulnificus presenting as septic arthritis. Arch. Intern. Med. 161, 2616-2618. doi: 10.1001/archinte.161.21.2616

Jones, J. L. (2014). Introduction, including Vibrio parahaemolyticus, Vibrio vulnificus, and other Vibrio Species. Mol. Medic. Microbiol. 3, 2237-2242. doi: 10.1016/b978-0-12-384730-0.00345-1

Jones, M. K., and Oliver, J. D. (2009). Vibrio vulnificus: disease and pathogenesis. Infect. Immun. 77, 1723-1733. doi: 10.1128/IAI.01046-08 
Jung, C. R., Park, M. J., and Heo, M. S. (2005). Immunization with major outer membrane protein of Vibrio vulnificus elicits protective antibodies in a murine model. J. Microbiol. 43, 437-442.

Karunasagar, I. (2014). "Vibrio Vulnificus," in Encyclopaedia of Food Safety, eds Y. Motarjemi, G. Moy, and E. Tood (Elsevier), 564-569.

Kashimoto, T., Ueno, S., Hayashi, H., Hanajima, M., Yoshioka, K., Yoshida, K., et al. (2005). Depletion of lymphocytes, but not neutrophils, via apoptosis in a murine model of Vibrio vulnificus infection. J. Med. Microbiol. 54, 15-22. doi: 10.1099/jmm.0.45861-0

Kim, J. H., Choresca, C. H. Jr., Shin, S. P., Han, J. E., Jun, J. W., and Park, S. C. (2011). Occurrence and antibiotic resistance of Vibrio Vulnificus in seafood and environmental waters in Korea. J. Food. Saf. 31, 518-524. doi: 10.1111/j.1745-4565.2011.00329.x

Klontz, K. C., Lieb, S., Schreiber, M., Janowski, H. T., Baldy, L. M., and Gunn, R. A. (1988). Syndromes of Vibrio vulnificus infections. Clinical and epidemiologic features in Florida cases, 1981-1987. Ann. Intern. Med. 109:318. doi: 10.7326/0003-4819-109-4-318

Koch, R. (2004). Vibrio-vulnificus-Infektion: Zwei Schwere Erkrankungsverlaufe. Epidermiologisches Bull. 13, 105-106.

Krovacek, K., Baloda, S. B., Dumontet, S., and Mansson, I. (1994). Detection of potential virulence markers of Vibrio vulnificus strains isolated from fish in Sweden. Comp. Immunol. Microbiol. Infect. Dis. 17, 63. doi: 10.1016/0147-9571(94)90007-8

Kuo, Y. L., Shieh, S. J., Chiu, H. Y., and Lee, J. W. (2007). Necrotizing fasciitis caused by Vibrio vulnificus: epidemiology, clinical findings, treatment and prevention. Eur. J. Clin. Microbiol. Infect. Dis. 26, 785-792. doi: 10.1007/s10096-007-0358-5

LaFrentz, B. R., and Shoemaker, C. A. (2015). Passive transfer of serum from tilapia vaccinated with a Vibrio vulnificus vaccine provides protection from specific pathogen challenge. Aquaculture 442, 16-20. doi: 10.1016/j.aquaculture.2015.02.025

Lee, H. J., Kim, J. A., Lee, M. A., Park, S. J., and Lee, K. H. (2013). Regulation of haemolysin (VvhA) production by ferric uptake regulator (Fur) in Vibrio vulnificus: repression of vvhA transcription by Fur and proteolysis of VvhA and Fur-repressive exproteases. Mol. Microbiol. 88, 813-826. doi: 10.1111/mmi.12224

Lee, K. M., Yoon, M. Y., Park, Y., Lee, J. H., and Yoon, S. S. (2011). Anaerobiosis-induced loss of cytotoxicity is due to inactivation of quorum sensing in Pseudomonas aeruginosa. Infect. Immun. 70, 2792-2800. doi: 10.1128/IAI.01361-10

Lee, M. A., Kim, J. A., Yang, Y. J., Shin, M. Y., Park, S. J., and Lee, K. H. (2014). VvpM, an extracellular metalloprotease of Vibrio vulnificus, induces apoptotic death of human cells. J. Microbiol. 52, 1036-1043. doi: 10.1007/s12275-014-4531-0

Lee, T. H., Kim, M. H., Lee, C. S., Lee, J. H., Rhee, J. H., and Chung, K. M. (2014). Protection against Vibrio vulnificus infection by active and passive immunization with the C-terminal region of the RtxA1/MARTXVv protein. Vaccine 32, 271-276. doi: 10.1016/j.vaccine.2013.11.019

Letchumanan, V., Chan, K.-G., and Lee, L.-H. (2014). Vibrio parahaemolyticus: a review on the pathogenesis, prevalence and advance molecular identification techniques. Front. Microbiol. 5:705. doi: 10.3389/fmicb.2014.00705

Letchumanan, V., Chan, K.-G., and Lee, L.-H. (2015b). An insight of traditional plasmid curing in Vibrio species. Front. Microbiol. 6:735. doi: $10.3389 /$ fmicb. 2015.00735

Letchumanan, V., Yin, W.-F., Lee, L.-H., and Chan, K.-G. (2015a). Prevalence and antimicrobial susceptibility of Vibrio parahaemolyticus isolated from retail shrimps in Malaysia. Front. Microbiol. 6:33. doi: 10.3389/fmicb.2015.00033

Letchumanan, V., Yin, W.-F., Lee, L.-H., and Chan, K.-G. (2015c). Prevalence and antimicrobial susceptibility of Vibrio parahaemolyticus isolated from retail shrimps in Malaysia. Front. Microbiol. 6:33. doi: 10.3389/fmicb.2015.00033

Levy, S. B., and Marshall, B. (2004). Antibacterial resistance worldwide: causes, challenges and responses. Nat. Medic. 10, S122-S129. doi: 10.1038/nm1145

Li, J., Yie, J., Fu, W., Foo, R. W., Hu, Y.,Woo, N. Y., et al. (1999). Antibiotic resistance and plasmid profiles of vibrio isolates from cultured silver sea brea, Sparus sarba. Mar. Pollut. Bull. 39, 245-249.

Liu, J. W., Lee, I. K., Tang, H. J., ko, W. C., Lee, H. C., Liu, Y. C., et al. (2006). Prognostic factors and antibiotics in Vibrio vulnificus septicaemia. Arch. Intern. Med. 166, 2117-2123. doi: 10.1001/archinte.166.19.2117
Manjusha, S., and Sarita, G. B. (2011). Plasmid associated antibiotic resistance in Vibrio isolated from coastal waters of Kerala. Int. Food Res. J. 18, 1171-1181.

Matsumoto, K., Ohshinge, K., Fujita, N., Tomita, Y., Mitsumizo, S., Nakashima, M., et al. (2010). Clinical features of Vibrio vulnificus infections in the coastal areas of the Ariake Sea. Jpn. J. Infect. Chemother. 16, 272-279. doi: 10.1007/s10156-010-0050-Z

Matsuoka, Y., Nakayama, Y., Yamada, T., Nakagawachi, A., Matsumoto, K., Nakamura, K., et al. (2013). Accurate diagnosis and treatment of Vibrio vulnificus infection: a retrospective study of 12 cases. Braz. J. Infect. Dis. 17, 7-12. doi: 10.1016/j.bjid.2012.07.017

Miyoshi, S., and Shinoda, S. (2000). Microbial metalloproteases and pathogenesis Microbes Infect. 2, 91-98. doi: 10.1016/S1286-4579(00)00280-X

Moreno, M. L., and Landgraf, M. (1998). Virulence factors and pathogenicity of Vibrio vulnificus strains isolated from seafood. J. Appl. Microbiol. 84, 747. doi: 10.1046/j.1365-2672.1998.00404.x

Motes, M. L., DePaola, A., Cook, D. W., Veazey, J. E., Hunsucker, J. C., Garthright, W. E., et al. (1998). Influence of water temperature and salinity on Vibrio vulnificus in Northern Gulf and Atlantic Coast oysters (Crassostrea virginica). Appl. Environ. Microbiol. 64, 1459-1465.

Mouzopoulos, G., Stamatakos, M., Tzurbakis, M., Batanis, G., Michou, E., Mouzopoulos, D., et al. (2008). Lower extremity infections by Vibrio vulnificus. Chirurgia (Bucur). 103, 201-203.

Nealson, K. H., Platt, T., and Hastings, J. W. (1970). Cellular control of the synthesis and activity of the bacterial luminescence system. J. Bacteriol. 104, 313-322.

Ng, W. L., and Bassler, B. L. (2009). Bacterial quorum-sensing network architectures. Annu. Rev. Genet. 43, 197-222. doi: 10.1146/annurev-genet-102108-134304

NSSP (2005). Florida Vibrio vulnificus Risk Reduction Plan for Oysters. National Shellfish Sanitation Program, US Food and Drug Administration.

Okoh, A. I., and Igbinosa, E. O. (2010). Antibiotic susceptibility profiles of some Vibrio strains isolated from wastewater final effluents in a rural community of the Eastern Cape Province of South Africa. BMC Microbiol. 10:143. doi: 10.1186/1471-2180-10-143

Oliver, J. D. (2005). Wound infections caused by Vibrio vulnificus and other marine bacteria. Epidemiol. Infect. 2, 177-188. doi: 10.1017/s0950268805003894

Oliver, J. D. (2006a). "Vibrio vulnificus," in Oceans and Health: Pathogens in the Marine Environment, eds S. Belkin and R. R. Colwell (New York, NY: Springer Science), 253-276. doi: 10.1128/9781555815714.ch25

Oliver, J. D. (2006b). “Vibrio vulnificus,"in Biology of Vibrios, eds F. L. Thompson, B. Austin, and J. Swing (Washington, DC: American Society for Microbiol), 349-366. doi: 10.1128/9781555815714.ch25

Oliver, J. D. (2013). Vibrio vulnificus: death on the half shell. A personal journey with the pathogen and its ecology. Microb. Ecol. 65, 793-799. doi: 10.1007/s00248-012-0140-9

Oliver, J. D., Warner, R. A., and Cleland, D. R. (1983). Distribution of Vibrio vulnificus and other lactose-fermenting vibrios in the marine environment. Appl. Environ. Microbiol. 45, 985-998.

Ottaviani, D., Bacchiocchi, I., Masini, L., Francesca, L., Carraturo, A., Giammarioli, M., et al. (2001). Antimicrobial susceptibility of potentially pathogenic halophilic vibrios isolated from seafood. Int. J. Antimicrob. Agents 18, 135-140. doi: 10.1016/S0924-8579(01)00358-2

Pan, J., Zhang, Y., Jin, D., Ding, G., Luo, Y., Zhang, J., et al. (2013). Molecular characterization and antibiotic susceptibility of Vibrio vulnificus in retail shrimps in Hangzhou, People's Republic of China. J. Food Prot. 76, 2063-2068. doi: 10.4315/0362-028X.JFP-13-161

Park, K. H., Jing, S. I., Jung, Y. S., Shin, J. H., and Hwang, J. H. (2009). Marine bacteria as a leading cause of necrotizing fasciitis in coastal areas of South Korea. Am. J. Trop. Med. Hyg. 80, 646-650.

Patridge, D. G., Townsend, R., Larkin, S., and Parsons, H. K. (2009). Vibrio vulnificus: an unusual mode of acquisition and novel use of rapid susceptibility testing. J. Clin. Pathol. 62, 370-372. doi: 10.1136/jcp.2008.059238

Penland, R. L., Boniuk, M., and Wilhelmus, K. R. (2000). Vibrio ocular infections on the U. S. Gulf Coast. Cornea 19, 26-29. doi: 10.1097/00003226-200001000-00006

Ralston, E. P., Powell, H. K., and Beet, A. (2011). An estimate of the cost of acute health effects from food- and water-borne marine pathogens and toxins in the USA. J. Water Health 680-694. doi: 10.2166/wh.2011.157 
Reboucas, R. H., Sousa, O. V., Lima, A. S., Vasaconcelos, F. R., de Carvalho, P. B., and Vieira, R. H. (2011). Antimicrobial resistance profile of Vibrio species isolated from marine shrimp farming environments (Litopenaeus Vannamei) at Ceará, Brazil. Environ. Res. 111, 21-24. doi: 10.1016/j.envres.2010.09.012

Rice, L. B. (2008). Federal funding for the study of antimicrobial resistance in nosocomial pathogens: no ESKAPE. J. Infect. Dis. 197, 1079-1081. doi: 10.1086/ 533452

Rodrigues, D. P., Ribeiro, R. V., and Hofer, E. (1992). Analysis of some virulence factors of Vibrio vulnificus isolated from Rio de Janeiro, Brazil. Epidemiol. Infect. 108, 463. doi: 10.1017/S0950268800049979

Shapiro, R. L., Altekruse, S., Hutwagner, L., Bishop, R., Hammond, R., Wilson, S., et al. (1998). The role of Gulf Coast oysters harvested in warmer months in Vibrio vulnificus infections in the United States, 1988-1996. J. Infect. Dis. 178, 752-759. doi: 10.1086/515367

Shaw, K. S., Goldstein, R. E. R., He, X., Jacobs, J. M., Crump, B. C., and Sapkota, A. R. (2014). Antimicrobial susceptibility of Vibrio vulnificus and Vibrio parahaemolyticus recovered from recreational and commercial areas of Chesapeake Bay and Maryland Coastal Bays. PLoS ONE 9:e89616 . doi: 10.1371/journal.pone.0089616

Stevens, L. M., Bisno, A. L., Chambers, H. F., Delinger, E. P., Goldstein, S. J., Gorbach, S. L., et al. (2014). Practice Guidelines for the Diagnosis and Management of Skin and Soft Tissue Infections: 2014 Update by the Infectious Diseases Society of America. IDSA Practice Guidelines for SSTIs.

Strom, M. S., and Paranjype, R. N. (2000). Epidemiology and pathogenesis of Vibrio vulnificus. Microb. Infect. 2, 177-188. doi: 10.1016/S1286-4579(00)00270-7

Sudha, S., Mridula, C., Silvester, R., and Hatha, A. A. (2014). Prevalence and antibiotic resistance of pathogenic vibrios in shellfishes from Cochin market. Indian J. Geo. Mar. Sci. 43, 815-824.

Tendencia, E. A., and de la Peña, D. L. (2001). Antibiotic resistance of bacteria from shrimp ponds. Aquaculture 195, 193-204. doi: 10.1016/S0044-8486(00) 00570-6

Torres, L., Escobar, S., Lopez, A. I., Marco, M. L., and Pobo, V. (2002). Wound Infection due to Vibrio vulnificus in Spain. Eur. J. Clin. Microbiol. Infect. Dis. 21, 537-538. doi: 10.1007/s10096-002-0767-4

Tsai, Y. H., Huang, K. C., Shen, S. H., Hsu, W. H., Peng, K. T., and Huang, T. J. (2012). Microbiology and surgical indicators of necrotizing fasciitis in a tertiary hospital of southwest Taiwan. Int. J. Infect. Dis. 16, 159-165. doi: 10.1016/j.ijid.2011.11.001
Tsai, Y. H., Huang, T. J., Hsu, R. W., Weng, Y. J., Hsu, W. H., Huang, K. C., et al. (2009). Necrotizing soft-tissue infections and primary sepsis caused by Vibrio vulnificus and Vibrio cholera non-O1. J. Trauma 66, 899-905. doi: 10.1097/TA.0b013e31816a9ed3

Vaseeharan, B., Ramasamy, P., Murugan, T., and Chen, J. C. (2005). In vitro susceptibility of antibiotics against Vibrio spp. and Aeromonas spp. isolated from Penaeus monodon hatcheries and ponds. Int. J. Antimicrob. Agents 26, 285-291. doi: 10.1016/j.ijantimicag.2005.07.005

Vugia, D. J., Tabnak, F., Newton, A. E., Hernandez, M., and Griffin, P. M. (2013). Impact of 2003 state regulation on raw oyster-associated Vibrio vulnificus illnesses and deaths, California, USA. Emer. Infect. Dis. 19, 1276-1280. doi: 10.3201/eid1908.121861

WHO (2014). Antimicrobial Resistance Global Report on Surveillance. World Health Organization. Available online at: http://www.who.int/drugresistance/ documents/surveillancereport/en/

Yun, N. R., Kim, D. M., Lee, J., and Han, M. A. (2015). pH level as a marker for predicting death among patients with Vibrio vulnificus infection, South Korea, 2000-2011. Emer. Infect. Dis. 21, 259-264. doi: 10.3201/eid2102. 131249

Zaidenstein, R., Sadik, D., Lerner, L., Valinsky, L., Kopelowitz, J., Yishai, R., et al. (2008). Clinical characteristics and molecular subtyping of Vibrio vulnificus illnesses, Israel. Emerg. Infect. Dis. 14, 1875-1882. doi: 10.3201/eid1412. 080499

Zanetti, S., Spanu, T., Deriu, A., Romano, L., Sechi, L. A., and Fadda, G. (2001). In vitro susceptibility of Vibrio spp. isolated from the environment. Int. J. Antimicrob. Agents 17, 407-409. doi: 10.1016/S0924-8579(01)00307-7

Conflict of Interest Statement: The authors declare that the research was conducted in the absence of any commercial or financial relationships that could be construed as a potential conflict of interest.

Copyright (c) 2017 Heng, Letchumanan, Deng, Ab Mutalib, Khan, Chuah, Chan, Goh, Pusparajah and Lee. This is an open-access article distributed under the terms of the Creative Commons Attribution License (CC BY). The use, distribution or reproduction in other forums is permitted, provided the original author (s) or licensor are credited and that the original publication in this journal is cited, in accordance with accepted academic practice. No use, distribution or reproduction is permitted which does not comply with these terms. 